\title{
ASPEK PERLINDUNGAN ANAK \\ DALAM TINDAK KEKERASAN (BULLYING) TERHADAP SISWA \\ KORBAN KEKERASAN DI SEKOLAH \\ (Studi Kasus di SMK Kabupaten Banyumas)
}

\author{
Oleh: \\ Muh a m mad \\ Sekolah Tinggi Agama Islam Al Ghazali Cilacap
}

\begin{abstract}
Children is nation future asset and router generation dream of nation, so children is entitled to the continuity of life, grow, and expand, participating and entitled of protection from discrimination and also have civil rights and freedom. These days there are aggressive behaviors and depress to the children, in the form of physical action and bullying that happened in education environment start from base level till college. From research result, physical bullying counted 9 times; verbal bullying counted 14 times and of bullying physical/ mental counted 8 times. This Bullying done by psychical and verbal. Bullying cause separate impact for student. Legal protection of student at school arranged in Law No.32 year 2002 concerning Protection of child.
\end{abstract}

Kata Kunci: anak, bullying, perlindungan hukum

\section{A. Pendahuluan}

Anak merupakan aset masa depan bangsa dan generasi penerus cita-cita bangsa, sehingga setiap anak berhak atas kelangsungan hidup, tumbuh, dan berkembang, berpartisipasi serta berhak atas perlindungan dari tindak kekerasan dan diskriminasi serta hak sipil dan kebebasan.

Pasal 1 Undang-undang Nomor 23 tahun 2002 tentang Perlindungan Anak menyebutkan bahwa Perlindungan Anak adalah:

Segala kegiatan untuk menjamin dan melindungi anak dan hak-haknya agar dapat hidup, tumbuh, berkembang, dan berpartisipasi, secara optimal sesuai dengan harkat dan martabat kemanusiaan, serta mendapat perlindungan dari kekerasan dan diskriminasi.

Proses perkembangan dan pertumbuhan anak akan sangat berpengaruh terhadap pembentukan karakter dan kualifikasi anak di masa depan. Jika dalam proses tumbuh kembangnya, anak sering mendapatkan perlakuan kasar atau bahkan mendapat tindakan kekerasan, maka proses pembentukan kepribadiannya akan terganggu. Anak adalah pemegang estafet kepemimpinan, sehingga perlindungan terhadap anak merupakan masalah yang harus diperhatikan.

Dewasa ini banyak dijumpai perilaku agresif dan menekan, baik dalam bentuk tindakan fisik secara langsung dan/atau menyerang melalui kata-kata atau disebut bullying, terjadi di lingkungan pendidikan mulai dari tingkat yang paling dasar hingga perguruan tinggi. Pelakunya tidak hanya para senior, tetapi juga guru, orang tua, dan lingkungan. ${ }^{1}$ Dari bulan Januari sampai Juni 2007, Komisi Nasional Perlindungan Anak (Komnas PA) memperoleh laporan 326 kasus bullying yang terjadi di wilayah Jabodetabek. Kasus bullying yang dilaporkan pada tahun 2005 sebanyak 292 kasus, yang berarti terjadi peningkatan kasus bullying yang sangat besar. ${ }^{2}$

Sri Hartati Samhadi. Budaya Kekerasan di Lembaga Pendidikan. http://www.kompas.co.id/kompas-cetak/0704/14/Fokus/3456065.htm. h. 1. Diakses tanggal 10 Desember 2007.

2 Yanuar Jatmika. Pendidikan dan Kebudayaan Perlu 
Istilah Bullying merupakan istilah yang masih baru dalam perbendaharaan kata dalam bahasa Indonesia. Sampai saat ini belum ada padanan kata yang tepat untuk kata bullying dalam bahasa Indonesia. Menurut Ketua Yayasan Sejiwa Diena Haryana, secara sederhana bullying diartikan sebagai penggunaan kekuasaan atau kekuat-an untuk menyakiti seseorang atau kelompok sehingga korban merasa tertekan, trauma, dan tidak berdaya. Bentuk bullying terbagi tiga, pertama: bersifat fisik seperti me-mukul, menampar, memalak. Kedua, bersifat verbal seperti: memaki, menggosip, mengejek dan ketiga bersifat psikologis, seperti: mengintimidasi, mengucilkan, mengabaikan, mendiskriminasi. ${ }^{3}$

Penelitian ini akan melihat aspek perlindungan anak dalam tindak kekerasan terhadap siswa di sekolah. Mengingat akhirakhir ini banyak kasus bullying mencuat ke permukaan. Guna melihat bagaimana aspek perlindungan anak dari bullying, penelitian ini akan dimulai dengan menguraikan bentukbentuk bullying, dampak bullying bagi anak, dan menguraikan aspek perlindungan anak dari bullying.

Secara sederhana alur pikir tesis ini berangkat dari desain utama perlindungan anak yang di dalamnya meliputi: Pertama, perlindungan anak secara umum seperti pelaksanaan, pemajuan dan penghormatan hakhak dasar anak sebagai bagian dari isu HAM. Kedua, perlindungan anak secara khusus yang terbagi dalam perlindungan bagi anak yang tersandung masalah hukum dan perlindungan anak bagi korban tindak kejahatan. Tesis ini akan mengkhususkan mengambil aspek perlindungan bagi anak sebagai siswa korban bullying, dan dengan analisis viktimologi. Penelitian ini akan menekankan pada aspek perlindungan korban yang dalam kajian ilmu hukum dikenal dengan kajian viktimologi. Zvonimir-Paul Separovic (1985) mendefinisikan

Gerakan Bersama Atasi Bullying. http://www.jurnalnasional.com $/$ ?med=Koran\%2OHarian\&sec=Pendidikan\%2 Odan\%20Kebudayaan\&rbrk=\&id=23470. h. 1. Diakses tanggal 10 Desember 2007.

3 Seijiwa, 2008, Bullying Mengatasi Kekerasan Di Sekolah dan Lingkungan Sekitar Anak, Jakarta: Grasindo, hlm. 2 viktimologi sebagai ilmu yang berkaitan dengan studi terhadap korban (Victimology refers to science dealing with the study of victim). ${ }^{4}$

Dari alur pikir di atas, tesis ini akan mengurai tiga permasalahan dasar, yaitu: pertama, bentuk-bentuk kekerasan terhadap anak di sekolah/bullying. Kedua, dampak kekerasan terhadap anak di sekolah/bullying dan ketiga, perlindungan anak dari tindakan kekerasan di seko-lah/bullying.

Informan penelitian adalah siswa korban tindak kekerasan dan guru SMK di Purwokerto Kabupaten Banyumas. Teknik penetapan informan pada penelitian kualitatif dengan menggunakan purposive sampling, yaitu teknik penentuan sampel untuk tujuan tertentu. ${ }^{5}$ Dalam hal ini adalah informan yang dianggap mengetahui tentang terjadinya kekerasan (bullying) di sekolah yaitu Guru Bimbingan dan Konseling, Siswa, Kepala Sekolah, Anggota Polisi bagian pengaduan di Polres Purwokerto dan Lembaga Swadaya Masyarakat. Sumber data primer dalam penelitian ini adalah kepala sekolah, Guru, siswa, Kepolisian bagian pengaduan di Polres Purwokerto dan Lembaga Swadaya Masyarakat di Kabupaten Banyumas.

\section{B. Pembahasan}

Bullying sebagai nama baru untuk mengidentifikasi situasi dimana terjadi penyalahgunaan kekuatan/kekuasaan yang dilakukan oleh seseorang/sekelompok, pada dasarnya bukan fenomena baru. Di sekolah khususnya, sudah tertanam tradisi atau pameo yang mengatakan: di ujung rotan ada emas. Artinya kekerasan dianggap sah dalam rangka menegakan pendidikan dan pembelajaran terhadap siswa.

Di sekolah bersama teman-temannya, siswa belajar mengembangkan dirinya, mengembangkan rasa kemasyarakatannya dan juga berlatih menjadi pemimpin. Keadaan yang demikian membantu si anak dalam menemukan jatidirinya. Dengan berteman terbentuk rasa

\footnotetext{
Iswanto dan Angkasa, 2007, Viktimologi, Purwokerto: Fakultas Hukum Universitas Jenderal Soedirman, hlm. 6 Sugiyono. 2006. Statistika Untuk Penelitian. Bandung: Alfabeta, hlm. 109
} 
solidaritas, menumbuhkan jiwa bersaing, berprestasi serta mengenali lingkungan. Pertemanan dan persaingan saling berhimpitan dan memungkinkan muncul tindak kekerasan ketika kepentingan salah satu diantaranya tidak terpenuhi. ${ }^{6}$

Dari hasil penelitian ditemukan bullying fisik terjadi sebanyak 9 kali, bullying verbal sebanyak 14 kali dan bullying mental/psikis sebanyak 8 kali.

Tabel .1

Jumlah Bullying

Data sekunder diolah

Yayasan SEJIWA mengidentifikasi jenis dan wujud bullying secara umum dapat dikelompokan ke dalam tiga kategori, yaitu: ${ }^{7}$

1. Bullying Fisik, meliputi tindakan: menam-

\begin{tabular}{|l|l|c|c|c|}
\hline No & \multicolumn{1}{|c|}{ Lokasi } & Fisik & Verbal & $\begin{array}{c}\text { Mental/ } \\
\text { Psikis }\end{array}$ \\
\hline 1 & SMK N 2 Purwokerto & 1 & 1 & - \\
\hline 2 & $\begin{array}{l}\text { SMK Bintek Purwo- } \\
\text { kerto }\end{array}$ & 2 & 3 & 2 \\
\hline 3 & $\begin{array}{l}\text { SMK Giri Puro Sum- } \\
\text { piuh }\end{array}$ & 1 & 2 & 1 \\
\hline 4 & $\begin{array}{l}\text { SMK Ma'arif 1 Sum- } \\
\text { piuh }\end{array}$ & 1 & 2 & 1 \\
\hline 5 & $\begin{array}{l}\text { SMK Kartek Jatil- } \\
\text { awang }\end{array}$ & 2 & 3 & 2 \\
\hline 6 & $\begin{array}{l}\text { SMK Tekom MBM } \\
\text { Rawalo }\end{array}$ & 2 & 2 & 1 \\
\hline \multicolumn{1}{|c|}{ Jumlah : } & 9 & 14 & 8 \\
\hline
\end{tabular}

par, menimpuk, menginjak kaki, menjegal, meludahi, memalak, melempar dengan barang, menghukum dengan berlari keliling lapangan dan menghukum dengan cara push up.

2. Bullying Verbal, terdeteksi karena tertangkap oleh indera pendengaran, seperti mema$\mathrm{ki}$, menghina, menjuluki, meneriaki, memalukan di depan umum, menuduh, menyoraki, menebar gosip, memfitnah dan menolak.

6 Ahmad Tafsir, 2001, Ilmu Pendidikan Dalam Prespektif Islam, Bandung: Rosda Karya, hlm. 173

7 Yayasan Semai Jiwa Amini (SEJIWA), 2008, Bullying : Mengatasi Kekerasan di Sekolah dan Lingkungan Sekitar Anak, Jakarta: Grasindo, hlm. 2
3. Bullying Mental/Psikologis, merupakan jenis Bullying yang paling berbahaya karena tidak tertangkap mata. Parktik ini terjadi secara diam-diam dan di luar pemantauan si korban. Contohnya adalah: memandang sinis, memandang penuh ancaman, mempermalukan di depan umum, mendiamkan, mengucilkan, mem-permalukan, meneror lewat pesan sms, memandang yang merendahkan, me-melototi, dan mencibir.

Dari hasil penelitian bullying yang terjadi di beberapa SMK di Kabupaten Banyumas diperoleh bentuk yang bervariasi. Bullying yang terjadi tidak hanya fisik tetapi juga psikis dan verbal. Bahkan ditengarahi bullying psikis ada yang memberi dampak akut berupa percobaan bunuh diri. Sebagai gambaran di bawah ini kami sajikan tabel bentuk-bentuk bullying di SMK di kabupaten Banyumas sebagai berikut :

Tabel.2

Bentuk-Bentuk Bullying

\begin{tabular}{|c|l|c|c|c|}
\hline No & \multicolumn{1}{|c|}{ Lokasi } & Fisik & Verbal & $\begin{array}{c}\text { Mental/ } \\
\text { Psikis }\end{array}$ \\
\hline 1 & $\begin{array}{l}\text { SMK N 2 } \\
\text { Purwokerto }\end{array}$ & Perkelahian & Ejekan & - \\
\hline 2 & $\begin{array}{l}\text { SMK Bintek } \\
\text { Purwokerto }\end{array}$ & $\begin{array}{l}\text { Perkelahian } \\
\text { pemukulan }\end{array}$ & $\begin{array}{c}\text { ejekan, } \\
\text { kata-kata } \\
\text { tidak sopan }\end{array}$ & $\begin{array}{c}\text { Pemalak- } \\
\text { an }\end{array}$ \\
\hline 3 & $\begin{array}{l}\text { SMK Giri Pu- } \\
\text { ro Sumpiuh }\end{array}$ & distrap & $\begin{array}{c}\text { Julukan yang } \\
\text { tidak sesuai }\end{array}$ & $\begin{array}{c}\text { Dicontek } \\
\text { dipalak }\end{array}$ \\
\hline 4 & $\begin{array}{l}\text { SMK Ma'arif } \\
\text { 1 Sumpiuh }\end{array}$ & Sanksi fisik & $\begin{array}{c}\text { Kata-kata } \\
\text { kotor }\end{array}$ & $\begin{array}{c}\text { Pengucila } \\
\mathrm{n}\end{array}$ \\
\hline 5 & $\begin{array}{l}\text { SMK Kartek } \\
\text { Jatilawang }\end{array}$ & $\begin{array}{l}\text { Perkelahian } \\
\text { pemukulan }\end{array}$ & $\begin{array}{c}\text { Kata-Kata } \\
\text { tidak Sopan, } \\
\text { Ejekan } \\
\text { cemoohan }\end{array}$ & $\begin{array}{c}\text { pengucila } \\
\mathrm{n}\end{array}$ \\
\hline 6 & $\begin{array}{l}\text { SMK Telkom } \\
\text { MBM Rawalo }\end{array}$ & $\begin{array}{l}\text { Perkelahian } \\
\text { pemukulan }\end{array}$ & $\begin{array}{c}\text { Ejekan } \\
\text { Cemoohan } \\
\text { dijahili }\end{array}$ & $\begin{array}{c}\text { Intimidasi } \\
\text { pema- } \\
\text { lakan }\end{array}$ \\
\hline
\end{tabular}

Data Sekunder diolah

Jika dihubungkan dengan teori di atas, maka bullying yang terjadi di SMK Bintek Purwokerto berupa kekerasan anak secara psikis yaitu penghardikan dan penyampaian kata-kata kasar dan kotor. Di SMK TEKOM terjadi bullying fisik berupa perkelahian antar siswa, pemukulan oleh guru. Bahkan bullying mental yang berupa intimidasi oleh TU untuk segera membayar tunggakan SPP hampir menelan nyawa satu orang siswa. Terjadi pula pemalakan oleh siswa kepada siswa lain yang 
Aspek Pelindungan Anak dalam Tindak Kekerasan (Bullying) 233 Terhadap Siswa Korban Kekerasan di Sekolah

sempat meresahkan be-berapa siswa. Bullying verbal yang ada berupa perkataan yang tidak baik/ejekan. Di SMK Giri Puro terjadi perkelahian. Di SMK Kartek juga terjadi kenakalan siswa. Meski-pun demikian, untuk kasus perkelahian tidak dapat secara langsung dikatakan sebagai bullying, karena pemukulan dilakukan oleh kedua belah pihak. Artinya keduanya dapat menjadi pelaku dan sekaligus sebagai korban. Di SMK N 2 Purwokerto bullying masih relatif jarang, yang muncul adalah bullying fisik berupa perkelahian dan bullying verbal berupa ejekan.

Dari hasil penelitian dapat diketahui bahwa bullying di sekolah, khususnya di SMK yang ada di Kabupaten Banyumas sudah terjadi, meskipun intensitasnya tidak tinggi. Dari penelitian juga ditemukan bahwa lebih banyak bullying terjadi siswa antar siswa. Sebaliknya tidak terungkap bullying yang dilakukan oleh guru, karyawan atau kepala sekolah. Padahal, dalam wawancara bebas dengan beberapa siswa di berbagai sekolah, mereka menuturkan banyak guru yang terbiasa berkata kasar, menghukum, memukul dengan lidi serta melempari kapur.

Bullying antar siswa secara teori memang sangat mudah terjadi mengingat usia anak SMK ada pada usia yang labil. Dalam Psikologi remaja perkelahian dapat dilihat sebagai bentuk kenakalan siswa. Hal ini dapat dirujuk dari pendapat Kartini Kartono yang menjelaskan tentang kenakalan remaja sebagai gejala sakit (patologis) secara sosial pada anakanak dan remaja yang disebabkan oleh satu bentuk pengabaian sosial, sehingga mereka itu mengembangkan bentuk tingkah laku yang menyimpang. Berbagai bentuk kenakalan remaja tersebut antara lain ada-lah kebutkebutan di jalanan yang mengganggu keamanan lalu-lintas, dan mem-bahayakan jiwa sendiri serta orang lain, perilaku ugal-ugalan, brandalan, urakan yang mengacaukan ketentraman milieu (lingkungan) sekitar, perkelahian antar gang, antar kelompok, membolos sekolah dan ber-gelandangan di jalan dan lain sebagainya. ${ }^{8}$
Tabel.3 Dampak-Dampak Bullying

Data Sekunder diolah

Berdasarkan data tersebut terdapat persesuaian antara teori yang mengatakan bullying

\begin{tabular}{|c|c|c|c|c|}
\hline No & Lokasi & Fisik & Verbal & $\begin{array}{c}\text { Mental/ } \\
\text { Psikis }\end{array}$ \\
\hline 1 & $\begin{array}{l}\text { SMK N } 2 \\
\text { Purwokerto }\end{array}$ & Memar & $\begin{array}{l}\text { Tidak } \\
\text { Masuk }\end{array}$ & - \\
\hline 2 & $\begin{array}{l}\text { SMK Bintek } \\
\text { Purwokerto }\end{array}$ & $\begin{array}{c}\text { Benjol } \\
\text { Luka } \\
\text { Tangan }\end{array}$ & $\begin{array}{l}\text { Gaduh } \\
\text { Kelas, } \\
\text { Tidak } \\
\text { Nyaman }\end{array}$ & $\begin{array}{c}\text { Tidak } \\
\text { Sekolah, } \\
\text { Depresi }\end{array}$ \\
\hline 3 & $\begin{array}{l}\text { SMK Giri } \\
\text { Puro } \\
\text { Sumpiuh }\end{array}$ & $\begin{array}{c}\text { Pusing } \\
\text { malu }\end{array}$ & $\begin{array}{c}\text { Tidak } \\
\text { Konsentras } \\
\text { i, Minder }\end{array}$ & $\begin{array}{c}\text { Tidak } \\
\text { Nyaman, } \\
\text { Takut }\end{array}$ \\
\hline 4 & $\begin{array}{l}\text { SMK } \\
\text { Ma'arif } 1 \\
\text { Sumpiuh }\end{array}$ & $\begin{array}{c}\text { Sering } \\
\text { Capek } \\
\text { Dan Tidak } \\
\text { Sekolah }\end{array}$ & $\begin{array}{l}\text { Gaduh } \\
\text { Kelas }\end{array}$ & $\begin{array}{l}\text { Minder, } \\
\text { Malu }\end{array}$ \\
\hline 5 & $\begin{array}{l}\text { SMK Kartek } \\
\text { Jatilawang }\end{array}$ & $\begin{array}{c}\text { Lecet, Tidak } \\
\text { Sekolah }\end{array}$ & $\begin{array}{l}\text { Gaduh } \\
\text { Kelas, } \\
\text { Tidak } \\
\text { Nyaman }\end{array}$ & $\begin{array}{c}\text { Tidak } \\
\text { Sekolah, } \\
\text { Depresi }\end{array}$ \\
\hline 6 & $\begin{array}{l}\text { SMK Tekom } \\
\text { MBM } \\
\text { Rawalo }\end{array}$ & $\begin{array}{c}\text { Luka Kening } \\
\text { Dada Sakit } \\
\text { dan Memar } \\
\text { serta tidak } \\
\text { sekolah }\end{array}$ & $\begin{array}{l}\text { Tidak } \\
\text { betah }\end{array}$ & $\begin{array}{c}\text { Depresi, } \\
\text { ingin } \\
\text { bunuh } \\
\text { diri, } \\
\text { tidak } \\
\text { betah }\end{array}$ \\
\hline
\end{tabular}

adalah penghambat besar bagi seorang anak untuk mengaktualisasi diri. Data di atas menunjukan Bullying memberi rasa tidak aman dan nyaman, membuat para korban bullying merasa takut dan terintimidasi, rendah diri serta tak berharga, sulit berkonsentrasi dalam belajar, tidak tergerak untuk bersosialisasi dengan lingkungannya, enggan bersekolah, pribadi yang tak percaya diri dan sulit berkomunikasi, sulit berpikir jernih sehingga prestasi akademisnya dapat terancam.

Sebagai negara yang telah meratifikasi Konvensi Hak Anak melalui Keputusan Presiden (Keppres) No. 36 tahun 1990, Indo-nesia terikat secara yuridis dan politis atas segala ketentuan yang ada di dalam konvensi tersebut. Salah satu ketentuannya adalah Indonesia sebagai negara pihak (state party) harus memberikan laporan berkala kepada PBB tentang pelaksanaan dari isi Konvensi Hak Anak tersebut. Sebagai per-wujudan dari komitmen negara, Indonesia 
telah mengeluarkan Undang-undang Perindungan Anak No. 23 tahun 2002.

Ada dua bentuk perlindungan terhadap siswa dari tindakan bullying: Pertama, Pencegahan terjadinya bullying. Kedua, Perlindungan terhadap korban bullying. Selain perlindungan terhadap siswa yang bersifat pencegahan, ada pula perlindungan siswa korban bullying. perlindungan siswa korban bullying dilakukan agar siswa memperoleh pemulihan sebagai upaya menyeimbangkan kondisi siswa yang mengalami gangguan. Jika terdapat korban kejahatan, maka negara harus memerhatikan kebutuhan korban dengan cara peningkatan pelayanan maupun pengaturan hak. Perlindungan korban juga berhubungan dengan salah satu tujuan pemidanaan yaitu penyelesaian konflik. Dengan penyelesaian konflik yang ditimbulkan oleh adanya tindak pidana akan memulihkan keseimbangan dan mendatang-kan rasa damai dalam masyarakat. ${ }^{9}$

Apabila dicermati maka perlindungan hukum terhadap siswa di sekolah tampak pada beberapa aspek, yakni dari konsideran, diktum pasal-pasal yang tercantum di dalamnya maupun dalam penjelasan pasal-pasal UU No.32 tahun 2002 tentang Perlindungan anak. Diantaranya adalah : Pasal 54 Undang-undang Nomor 23 tahun 2002 tentang Perlindungan Anak disebutkan bahwa:

Anak di dalam dan di lingkungan sekolah wajib dilindungi dari tindakan kekerasan yang dilakukan oleh guru, pengelola sekolah atau teman-temannya di dalam sekolah yang bersangkutan, atau lembaga pendidikan lainnya"

Selanjutnya pada Undang-undang Nomor 23 tahun 2002 tentang Perlindungan Anak Bab III tentang Hak dan Kewajiban Anak Pasal 13 disebutkan:

1. Setiap anak selama dalam pengasuhan orang tua, wali atau pihak lain manapun yang bertanggung jawab atas pengasuhan, berhak mendapat perlindungan dari perlakuan: Diskriminasi, Eksploitasi baik ekonomi mapun seksual, Penelantaran, Kekejaman, kekerasan dan penganiayaan, Ketidakadilan, dan Perilaku salah lainnya.

2. Dalam hal orang tua, wali atau pengasuh anak melakukan segala bentuk perlakuan sebagaimana dimaksud pada ayat (1), maka pelaku dikenakan pemberatan hukuman.

Perlindungan bagi anak selanjutnya disebutkan pula pada pasal 16 yang menyebutkan bahwa :

1. Setiap anak berhak memperolah perlindungan dari sasaran penganiayaan, penyiksaan atau penjatuhan hukuman yang tidak manusiawi.

2. Setiap anak berhak untuk memperoleh kebebasan sesuai dengan hukum

3. Penangkapan, penahanan atau tindak pidana penjara anak hanya dilakukan jika sesuai dengan hukum yang berlaku dan hanya dapat dilakukan sebagai upaya terakhir.

Pada dasarnya perlindungan terhadap siswa di sekolah dapat ditinjau dari sudut pandang kebijakan kriminal. Kebijakan kriminal yaitu upaya penanggulangan kejahatan dengan pendekatan :

a. Ada keterpaduan (integralitas) antara politik kriminal dan politik sosial;

b. Ada keterpaduan (integralitas) antara upaya penanggulangan kejahatan dengan jalur "penal" dan "non-penal".

Sudarto mengemukakan, bahwa apabila hukum pidana hendak dilibatkan dalam usaha mengatasi segi-segi negatif dari perkembangan masyarakat/modernisasi (antara lain penanggulangan kejahatan), maka hendaknya harus melihat hubungan keseluruhan politik kriminal atau social defence planning, yang harus menjadi bagian integral dari rencana pembangunan nasional.

Upaya penanggulangan kejahatan melalui kebijakan kriminal secara garis besar di bagi dua, yaiti: lewat jalur penal (hukum pidana) dan lewat jalur non penal (bukan/diluar hukum pidana). Upaya penyelesaian melalui jalur penal lebih menitikberatkan pada sifat represif (pemberantasan/penumpasan), sedangkan jalur non penal kebijakan ini lebih menitikberatkan 
pada sifat preventif (pencegahan penangkalan). ${ }^{10}$

Penelitian ini melihat dua kebijakan kriminal, yaitu jalur penal dan non penal, sangat berperan dalam menanggulangi kejahatan Bullying. Dua kebijakan tersebut tidak bisa dipilah-pilah, sebab kejahatan atau kekerasan terhadap siswa bisa datang dari mana saja. Artinya tindakan represif dan preventif keduanya sama-sama penting.

Meskipun masih jauh dari yang diharapkan, usaha memperhatikan korban sudah mulai dirintis misalnya tentang pra peradilan (Pasal 95 KUHAP) dan penggabungan tuntutan ganti rugi (restitusi) dalam proses pidana (Pasal 98101 KUHAP). Tentunya tindakan-tindakan konkrit sangat diperlukan untuk lebih melindungi dan memperhatikan hak-hak korban, baik yang berupa perangkat hukum maupun dalam penegakan hukumnya.

\section{Penutup}

Berdasarkan pada hasil penelitian dan pembahasan dapat disimpulkan sebagai berikut: Bentuk-bentuk tindak kekerasan (bullying) yang terjadi di SMK N 2 Purwokerto, SMK Bintek Purwokerto, SMK Kartek Jatilawang, SMK Tekom MBM Rawalo, SMK Giripuro Sumpiuh dan SMK Ma'arif NU 1 Sumpiuh, meliputi: Pertama: bentuk Bullying Fisik, berupa tindakan : berkelahi, memukul, penyetrapan, sanksi fisik, dan push up. Kedua, Bullying Verbal, berupa tindakan : mengejek, kata-kata tidak sopan, menjuluki yang tidak sesuai, kata-kata kotor, mencemooh dan menjahili. Ketiga, Bullying Mental/Psikologis, berupa tindakan: pemalakan, memaksa memberi contekan, mengucilkan, mengintimidasi.

Dampak tindak kekerasan (bullying) pada siswa di SMK N 2 Purwokerto, SMK Bintek Purwokerto, SMK Kartek Jatilawang, SMK Tekom MBM Rawalo, SMK Giripuro Sumpiuh dan SMK Ma'arif NU 1 Sumpiuh, meliputi : Pertama Dampak fisik seperti : memar, benjol, luka tangan, pusing, sering capek dan tidak sekolah,

10 Barda Nawawi Arif, 2005, Bunga Rampai Kebijakan Hukum Pidana, Bandung: PT Citra Aditya Bhakti, hlm. 42 lecet, luka kening, dada sakit, memar kepala dan tidak sekolah. Kedua, dampak bullying verbal berupa: tidak masuk kelas, suasana kelas gaduh, tidak nyaman untuk belajar, tidak konsentrasi dalam belajar, minder, dan tidak betah. Ketiga, dampak bullying psikis berupa: tidak sekolah, depresi, tidak nyaman dalam belajar, takut, minder, malu, ingin bunuh diri dan tidak betah sekolah.

Perlindungan anak terhadap tindak kekerasan (bullying) pada siswa secara umum dilindungi oleh Undang-undang No. 23 Tahun 2003 tentang Perlindungan Anak, antara lain terdapat pada Pasal 13, Pasal 16 dan Pasal 54. Perlindungan anak terhadap tindak kekerasan (bullying) pada siswa SMK di Kabupaten Banyumas dibagi dalam dua bentuk: Pertama, Pencegahan terjadinya bullying/kekerasan. Perlindungannya berupa: sosialisasi tata tertib sekolah, diskusi anti kekerasan berbasis gender, kegiatan ekstrakurikuler, penetapan mata pelajaran tertentu (seperti etika Islam, akhlak), sistem angka kredit pelanggaran, Bimbingan Konseling, surat peringatan serta sosialisasi anti narkoba. Kedua, Perlindungan siswa korban bullying. Perlindungannya berupa: Restitusi/ Kompensasi, Konseling, pelayanan medis/bantuan medis, bantuan hukum, dan pemberian informasi.

\section{Daftar Pustaka}

Abdul, Wahab Solichin. 1990. Analisis Kebijaksanaan dari Formulasi ke Implementasi Kebijaksanaan Negara. Jakarta: Bina Aksara;

Adi, Isbandi Rukinto. 2002. Pemikiran-Pemikiran Dalam Pembangunan Kesejahteraan Sosial. Jakarta: LPFE UI;

Ahmadi, Abu. 1991. Sosiologi Pendidikan. Jakarta: Rineka Cipta;

Arif, Barda Nawawi. 2005. Bunga Rampai Kebijakan Hukum Pidana. Bandung: PT Citra Aditya Bhakti;

Iswanto dan Angkasa. 2007. Viktimologi, Purwokerto: Fakultas Hukum Universitas Jenderal Soedirman;

Jatmika, Yanuar, Pendidikan dan Kebudayaan Perlu Gerakan Bersama Atasi Bullying, 
http: / / www.jurnalnasional.com/?med=K oran\%20Harian\&sec=Pendidikan\%20dan\%2 OKebudayaan\&rbrk=\&id=23470. h. 1 . Diakses tanggal 10 Desember 2007;

Kartono, Kartini. 2002. Patologi Sosial 2: Kenakalan Remaja. Jakarta: Raja Grafindo Persada;

Tafsir, Ahmad. 2001. Ilmu Pendidikan Dalam Prespektif Islam. Bandung: Rosda Karya;

Seijiwa, 2008, Bullying mengatasi kekerasan di sekolah dan lingkungan sekitar anak, Jakarta: Grasindo;

Sugiyono. 2006. Statistika Untuk Penelitian. Bandung: Alfabeta;

Samhadi, Sri Hartati. Budaya Kekerasan di
Lembaga Pendidikan, http://www.kompas.co.id/kompas-cetak/0704/14/Fokus/3456065.htm.h.1. Diakses tanggal 10 Desember 2007;

Yayasan Semai Jiwa Amini (SEJIWA). 2008. Bullying: Mengatasi Kekerasan di Sekolah dan Lingkungan Sekitar Anak. Jakarta: Grasindo.

Perundang-undangan :

Kitab Undang-Undang Hukum Pidana.

Undang-undang Nomor 23 tahun 2002 tentang Perlindungan Anak

Undang-undang Nomor 20 tahun 2003 tentang Sistem Pendidikan Nasiona 